\title{
Use of Grape Leaves for Producing Graphene for Use as an Oxygen Reduction Electrocatalyst
}

\author{
S. Sadegh Hassani ${ }^{1,2}$, M.R. Ganjali ${ }^{1,3, *}$, L. Samiee ${ }^{4}$ and A.M. Rashidi ${ }^{5}$ \\ ${ }^{1}$ Center of Excellence in Electrochemistry, School of Chemistry, College of Science, University of \\ Tehran, Tehran, Iran. \\ ${ }^{2}$ Catalysis Research Division, Research Institute of Petroleum Industry (RIPI), West Blvd. Azadi Sport \\ Complex, P.O. Box 14665-137, Tehran, Iran. \\ ${ }^{3}$ Biosensor Research Center, Endocrinology and Metabolism Molecular-Cellular Sciences Institute, \\ Tehran University of Medical Sciences, Tehran, Iran. \\ ${ }^{4}$ Energy Technology Research Division, Research Institute of Petroleum Industry (RIPI), West Blvd. \\ Azadi Sport Complex, P.O. Box 14665-137, Tehran, Iran. \\ ${ }^{5}$ Nanotechnology Research Center, Research Institute of Petroleum Industry (RIPI), West Blvd. Azadi \\ Sport Complex, P.O. Box 14665-137, Tehran, Iran. \\ "E-mail: ganjali@ut.ac.ir
}

doi: $10.20964 / 2020.05 .88$

Received: 2 February 2020 / Accepted: 18 March 2020 / Published: 10 April 2020

\begin{abstract}
Recently, the development of highly active electrocatalysts with considerable, efficiency and moderate costs for application in the oxygen reduction reaction (ORR) has attracted a great deal of attention. In this work, an economic and easy approach has been evaluated for preparation of graphene doped with N, S, B and P. The source of graphene used in this study was grape leaves and N, S, P and B were then added thereto through a 2-hour pyrolysis reaction in $\mathrm{N}_{2}$ atmosphere at $900^{\circ} \mathrm{C}$. The produced specimens were evaluated using XRD, FTIR, SEM, XPS ad TEM, as well as CV analyses using a rotating disk electrode (RDE). The morphology of doped graphene sample showed uniform dispersion of sulfur, nitrogen, boron and phosphorous in the carbon framework, which was obtained with elemental mapping distribution. The prepared samples show good selectivity to the 4 electron reaction pathway in an alkaline electrolyte as well as stable current density and great resistance against crossover effects of methanol. These indicate the considerable promise of these materials for use in oxygen reduction reaction as an electro-catalyst. Moreover, the onset potential of G1300G-900 and GlG-900 samples (0.93 and $0.92 \mathrm{~V}$ vs. RHE) was found to be near that of Pt/C 20 wt.\% (0.99 V vs RHE).
\end{abstract}

Keywords: Grape leaves, Alkaline fuel cell, Graphene, Metal-free catalyst, Oxygen reduction reaction (ORR)

\section{FULL TEXT}


(C) 2020 The Authors. Published by ESG (www.electrochemsci.org). This article is an open access article distributed under the terms and conditions of the Creative Commons Attribution license (http://creativecommons.org/licenses/by/4.0/). 